\title{
Política y Religión: Un enfoque para abordar las relaciones entre tradición y modernidad en la Independencia de la Nueva Granada (1808-1819)
}

\author{
Politics and Religion: \\ An approach to address the relationship between tradition \\ and modernity in the Independence of New Granada (1808-1819) \\ María del Rosario Vázquez Piñeros \\ Universidad de la Sabana - COLOMBIA \\ maria.vasquez@unisabana.edu.co
}

\section{Resumen}

El presente artículo es una reflexión sobre el enfoque, criterios y metodología para abordar la historia del pensamiento político-teológico durante la independencia de la Nueva Granada. De esta forma, plantea la relevancia de cuatro preguntas fundamentales sobre los tipos de fuentes, su autor, la motivación de dicho autor y la funcionalidad del documento. En este sentido, propone el análisis de cuatro niveles de realidad: fuente-autor, corrientes teológicas, tendencias intelectuales de la época y características del contexto histórico-cultural. Por último, plantea unos elementos característicos del pensamiento político-teológico: interpretación de la historia, concepción del poder y tipo de gobierno, fuentes éticas y legislación, relación entre la potestad civil y religiosa, y proyecto político (temporal y escatológico). Este tipo de análisis permite comparar tanto argumentos y, o elementos conceptuales comunes, como planteamientos político-teológicos opuestos; y, en este orden, dilucida la influencia del pensamiento Ilustrado propio del ámbito hispánico, en concepciones tan distintas como el Despotismo Ilustrado y el Liberalismo católico.

Palabras clave: Nueva Granada, independencia, pensamiento político-teológico, ilustración católica, historia de las ideas

\begin{abstract}
This article is a reflection on the approach, criteria and methodology to study the history of political-theological thought during the independence of New Granada. In this way, it raises the relevance of four fundamental questions about the types of sources, their author, the motivation of the author and the functionality of the document. It also proposes the analysis of four levels of reality: source-author, theological
\end{abstract}

María del Rosario Vázquez Piñeros

Política y Religión: Un enfoque para abordar las relaciones entre tradición y modernidad en la Independencia de la Nueva Granada (1808-1819) Autoctonía. Revista de Ciencias Sociales e Historia, Vol. IV, N¹, Enero-Junio 2020, 65-76 ISSN 0719-8213

DOI: http://dx.doi.org/10.23854/autoc.v4i1.153 
currents, intellectual trends of the time and characteristics of the historical-cultural context. Finally, it raises some characteristic elements of political-theological thought: history interpretation, conception of power and type of government, ethical sources and legislation, relationship between civil and religious power, and political project (temporal and eschatological). This type of analysis allows comparing both arguments and, or common conceptual elements, as opposed political-theological approaches; and, in this order, elucidated the influence of the Enlightened thought typical of the Hispanic sphere, in conceptions as different as Illustrated Despotism and Catholic Liberalism.

Keywords: New Granada, independence, political-theoligical thought, catholic enlightenment, history of ideas

Recibido: 07 de Junio de 2019 · Aceptado: 18 de Noviembre de 2019

\section{Introducción}

El presente artículo tiene como objetivo plantear reflexiones sobre el enfoque y la metodología para comprender e interpretar la influencia del pensamiento político-teológico en la Independencia de la Nueva Granada; así como analizar algunas conclusiones obtenidas a partir de dicha propuesta ${ }^{1}$. En este orden de ideas, es importante comenzar con una clasificación de los enfoques sobre las fuentes intelectuales del pensamiento independentista. El primero de estos, destaca la influencia de la neoescolástica propia del Renacimiento y del siglo XVIII (Gómez, 1962; Uprimny, 1952-1954). El segundo, explica la forma como influyó un tipo de modernidad característica del mundo hispánico en el contexto intelectual y político de la Independencia. Este tipo de modernidad fue inicialmente advertida por Francisco-Xavier Guerra, uno de los iniciadores de Escuela Cultural, corriente historiográfica que analiza el mundo de las ideas a partir de las costumbres y las formas de sociabilidades en que dicho pensamiento es vivenciado (Guerra, 1992). El tercero, subraya la instrumentalización política del discurso religioso. En esta línea, una investigación relativamente reciente emplea métodos estadísticos para evidenciar la citación de pasajes bíblicos en el púlpito con el fin de legitimar tanto la causa realista como independentista (Arce, 2012: 273307). Igualmente, el conceptualismo de Koselleck ha inspirado una serie de estudios sobre el ideario independentista en Hispanoamérica y la Nueva Granada. Así, el uso de palabras y el significado de las mismas, aportan a la comprensión sobre la influencia de la teología en la política, es decir, la repercusión del pensamiento político-teológico sobre el plano jurídico, institucional y temporal (VV.AA, 2009; Ortega y Chicangana-Bayona, 2012).

Además de la lectura de la bibliografía sobre esta temática, que ya, de por sí, es bastante amplia, la investigación sobre el pensamiento político-teológico en la Independencia de la Nueva Granada, conlleva a la consulta de obras clásicas de autores reconocidos, como por ejemplo: San Agustín 
(Artuñano, 2010), Santo Tomás (1960: 1089-1093), Bernardo de Claraval (2005: 39-79), Bossuet (1789: 234-258), Mariana (1950), Vitoria (1928; 1995: 129-135) y Francisco Suárez (1970), entre otros; así como de fuentes documentales: prensa, sermones, actas y obras literarias ${ }^{2}$, cuyos originales reposan en el Archivo General de la República de Colombia, en las Bibliotecas Nacional y Luis Ángel Arango, así como en el Archivo Histórico Cipriano Rodríguez Santa María ${ }^{3}$.

\section{Investigar la influencia del pensamiento po- lítico teológico en la Independencia de la Nueva Granada: enfoque y metodología.}

El enfoque que se propone en el presente artículo para abordar la historia del pensamiento político-teológico en la Independencia de la Nueva Granada, está orientado, en primer lugar, a identificar los argumentos alrededor de los cuales giraron las disputas a favor o en contra de la independencia, lo que supone tener en cuenta la influencia de este tipo de pensamiento en una sociedad del mundo hispánico a finales de Antiguo Régimen, como era el caso del Virreinato de la Nueva Granada. En este orden, retomamos las palabras de Josep Ignasi Saranyana (2011: 234235), cuando afirma que, en el transcurso de estas guerras, se conformaron tanto una "teología de la revolución" como una "teología de fidelismo".

Dado el sustrato cultural compartido por las dos partes, además de la identificación de dichos argumentos político-teológicos, planteamos un análisis comparativo que dé cuenta de la forma como cada uno de los bandos comprendieron y aplicaron conceptos comunes dado que estos hacían parte del pensamiento y la herencia intelectual católica. Por ejemplo, el origen divino del poder, la búsqueda del bien común, la justicia y la concepción providencial de la historia. Por otro lado, también es importante destacar que cada uno interpretó de forma diferente temas íntimamente relacionados, como, por ejemplo, la concepción del poder político: Absolutismo Vrs/Neoescolástica y Liberalismo; y los aspectos de jurisdicción eclesiástica relativos a la forma como debía ser gobernada la Iglesia, así como sus relaciones con el ámbito civil: Regalismo Vrs/Romanismo, respectivamente. En concreto, alrededor de estos grandes ámbitos giraron los principales debates político-teológicos de la independencia: la obligación de obediencia a los legítimos poderes civiles (San Pablo a los Romanos 13: 1-10), el concepto mismo de poder; el «gobierno según justicia» (Amores, 2011: 131-152); la noción providencial de la historia y la "guerra justa»; la legitimidad de la intervención del Papa en los temas temporales; y la autoridad de Roma frente a la monarquía y el episcopado (Vázquez, 2019: 345-355). De esta forma, conceptos y argumentos compartidos por una misma identidad católica, recibieron distintas interpretaciones y lecturas dependiendo de la postura política de quienes los usaron en sus discursos.

Por otro lado, el enfoque que proponemos retoma elementos propios de la Nueva Historia Intelectual y de sus distintas tradiciones. En este sentido, compartimos el punto de vista de Fernando Vallespín cuando sugiere evitar "radicalismos metodológicos" que limiten el análisis (2012:22). Por lo tanto, nuestro planteamiento no descarta el estudio de las sociabilidades (Historia Cultural); 
por el contrario, está abierto a la posibilidad de abordar la historia de las ideas con los aportes de dicha corriente historiográfica. E igualmente, aunque no pretenda la realización de una investigación histórica rigurosamente conceptual, reconoce que resultaindispensable tener en cuenta los aportes de dicha corriente historiográfica, en la medida en que vincula el análisis de textos con sus correspondientes contextos; y la historia de aquellos, su evolución, en relación con las transformaciones de las circunstancias históricas.

En todo caso, el factor común y esencial presente en esta forma de eclecticismo, es el lugar que ocupa la relación entre texto, autor y contexto. En este orden de ideas resulta indispensable tener en cuenta algunas particularidades del pensamiento teológico respecto a su estructura y su dinámica, en la medida en que su comprensión requiere considerar dos dimensiones: la primera, referida al pasado, esto es, a su anclaje en la tradición, dado que el pensamiento religioso presenta permanencias y continuidades de larga duración histórica ${ }^{4}$. La segunda se relaciona con las nuevas lecturas y reelaboraciones teológicas planteadas en las distintas épocas como resultado de los cambios históricos y culturales. Estas nuevas lecturas darán paso a posturas que respetan la ortodoxia en sus aspectos esenciales; a heterodoxias; o, en casos de disidencia más radical, a herejías y cismas. Esto significa, a su vez, que, al identificar los argumentos político-teológicos, proponemos tener en cuenta su relación con la historia de la teología en el contexto de la historia del cristianismo, en general, y de la Iglesia católica en particular, con sus distintas corrientes de pensamiento; así como explicar las similitudes y afinidades de estas, sus disidencias y conflictos, reconociendo las permanencias y transformaciones que se operan en las diferentes etapas socioculturales. En el caso de la Nueva Granada, en el período que abordamos, esto nos permite identificar corrientes político-teológicas afines con la tradición (Neoescolástica y Liberalismo Católico); y heterodoxias (Despotismo Ilustrado y Jansenismo). En cuanto a cismas o herejías, habría que hacer la salvedad de que, en el contex to objeto de estudio, no ocurrieron este tipo de fenómenos.

Por otra parte, el presente enfoque supone el planteamiento de unas preguntas y elementos referidos al texto, al autor y al contexto (niveles de realidad), con el fin de promover una interpretación global e integradora acerca de la actuación de los individuos, en el marco de los colectivos históricos que representan, así como de los contextos socioculturales y políticos en que se movieron. Igualmente, busca identificar los vínculos, contactos, coincidencias y disidencias entre los autores de dichos textos cuando estos se dieron. De esta forma, se destacan la interrelación de cuatro niveles de realidad. El primero, referido a la identificación de los argumentos en contra o a favor de la independencia, lo que supone el análisis de los textos (sermones, cartas, constituciones, proclamas, memorias, obras literarias, etc.); así como la identificación y descripción analítica de sus autores, destacando las peculiaridades biográficas y contextuales que explican su posición. En relación con este aspecto, consideramos importante comprender la relación dialéctica entre las convicciones de tipo teológico -en su dimensión trascendente, esto es, espiritual y ética- junto con los intereses y 
circunstancias individuales y colectivas que motivaron las actuaciones de dichos sujetos, y que, en la práctica, pueden guardar mayor o menor coherencia con dichos principios. Esta relación puede mostrar coherencias o inconsistencias. En todo caso, creemos necesario detectar y explicar las tensiones y variados matices entre estos dos aspectos de tipo motivacional que dan cuenta de la relación entre el discurso (planteamiento teórico) -es decir, las ideas político-teológicas contenidas en la fuente-con los intereses, circunstancias y la praxis de los autores y de los sujetos sociales que promueven dichos discursos. La intención, con esto, es superar reduccionismos de tipo funcionalista e instrumental, así como tomar distancia de interpretaciones idealistas que desvinculan los intereses y circunstancias de individuos y colectividades, de auténticas o supuestas convicciones de tipo político, religioso y moral.

En términos concretos, el análisis de fuentes ha de llevar a la identificación y comprensión de dos aspectos: por un lado, las convicciones político-religiosas que se reflejan en los textos; y, por otro, la intención pragmática perseguida con ellos. Encontrando que, en unos casos, las convicciones e intenciones prácticas coincidieron, como ocurría, por ejemplo, cuando un sacerdote, ferviente y convencido realista, redactaba un sermón para legitimar, entre sus fieles, la Reconquista española. Tal es el caso de Antonio de León, en su Discurso político moral (León, 1816). Pero también se ha evidenciado que, en otras ocasiones, primaron los objetivos instrumentales de quienes promovieron la redacción y difusión de estos escritos, con el fin principal de usar la religión como eficaz herramienta de poder y disciplina social. Un ejemplo de ello fue la orden, por parte del no muy piadoso Francisco de Paula Santander, vicepresidente de la Gran Colombia, de defender la obediencia a la nueva República desde los púlpitos (Arce, 2012: 304). No obstante, hay que aclarar que nos distanciamos de los enfoques funcionalistas que ven tras dichas fuentes y sus autores, únicamente intenciones instrumentales de tipo oportunista, sin comprender la genuina sensibilidad religiosa que muchas veces estuvo presente en la redacción de estos escritos. En todo caso, insistimos, este tipo de análisis no deben dejar de lado los usos instrumentales de la religión que efectivamente se llevaron a cabo, tanto por realistas como por republicanos.

De esta forma, el enfoque que proponemos, destaca la importancia de responder a cuatro preguntas fundamentales sobre: el qué (tipo y contenido, esto es, comprensión teórica del texto); quién (sobre su autor, el grupo o colectivo social que representa y su contexto); el por qué (motivaciones del autor); y el para qué (es decir, la funcionalidad del texto, que no necesariamente coincide con las convicciones del autor). En este orden, busca identificar las corrientes o escuelas político-teológicas en las que se inspiraron y sustentaron los argumentos político-teológicos defendidos durante la Independencia: Escolástica, Neoescolástica, Ilustración Católica, Despotismo Ilustrado, Regalismo y Jansenismo. En este punto es importante destacar que el teológico constituye una forma de pensamiento religioso, de carácter intelectual, por lo cual, sus propuestas, reflexiones y difusión se mueven en ámbitos selectivos, esto es, al interior de élites intelectuales y político-religiosas (Guerra, 1992: 175). Como tal, orienta 
$\mathrm{y}$ ofrece sentido a la experiencia trascendente y nutre las cosmovisiones en las que el elemento religioso es fuertemente condicionante; desde luego, sus postulados esenciales son asimilados en ambientes más generales, por otro tipo de públicos más amplios. Las manifestaciones de dicho pensamiento en estos contextos socioculturales más extensos, a nivel popular, ha sido objeto de estudio de la llamada Historia de las Mentalidades (Escuela de los Anales). Asimismo, en este punto es importante recordar que cada grupo sociocultural presenta lenguajes diferenciados. A esto se refiere Reinhart Koselleck, cuando habla sobre los "sociolectos", término con el que explica el diferenciado uso de conceptos por parte de distintos partidos, grupos o clases sociales (2004: 36-39). Por otra parte, el enfoque que planteamos, también propone explicar la relación del pensamiento político-teológico con las corrientes intelectuales de la época; por ejemplo, Racionalismo, Ilustración y Romanticismo. Y, por último, vincular los aspectos mencionados con las características del contexto sociocultural investigado; en el presente caso, la transición revolucionaria del Antiguo al Nuevo Régimen, en la Nueva Granada, virreinato que hizo parte del mundo cultural Hispánico.

Por lo tanto, el presente enfoque se orienta hacia un análisis que combina el estudio de los niveles de realidad aludidos, partiendo desde su base -en este caso, la comprensión del contexto socioculturalhasta sus manifestaciones concretas, evidenciadas en los textos y los sujetos históricos, es decir, en los autores de los mismos. Creemos que sólo una visión que conjugue estos distintos niveles de análisis permite una explicación integradora y una comprensión amplia en el ámbito de la historia de las ideas, en general, y del pensamiento político-teológico, en particular.

Asimismo, este planteamiento incluye un análisis de las que creemos constituyen algunas de las características propias del pensamiento político-teológico ${ }^{5}$. En primer lugar, encontramos que cada una de ellas realiza un análisis einterpretación del pasado histórico-religioso. En segundo término, relacionan dicha interpretación histórica con una concepción del poder, la cual se justifica y legitima desde la referencia a dicho pasado. Tercero, tal concepción del poder incluye una propuesta de gobierno fundamentada en unas directrices éticas-teológicas (teología moral) que orientan el comportamiento de los gobernantes y de los gobernados; en la tradición hispano-católica, esto hace referencia a la búsqueda del bien común y la justicia. En cuarto lugar, tales principios éticos se constituyen en fuente de inspiración legal; o de resistencia político-religiosa cuando las leyes no son coherentes con dichos principios. Quinto: igualmente, cada corriente político-teológica interpreta el tipo de relación que debe existir entre la potestad civil y la religiosa. Y, finalmente, orienta y da sentido a la actuación de los hombres en aras de alcanzar un proyecto político temporal que trasciende al plano escatológico. Con base en estas características que encontramos en el pensamiento político-teológico, creemos se facilita el análisis, por ejemplo, del Despotismo Ilustrado, el Absolutismo, Jansenismo y el Regalismo, por un lado; así como de la Escolástica, la Neoescolástica y el Liberalismo Católico, por otro. 
En este orden de ideas, se identificaron las siguientes corrientes político-teológicas como trasfondo de los argumentos planteados por realistas e independentistas en la Nueva Granada: la Escolástica del bajo medioevo, especialmente el pensamiento de Santo Tomás de Aquino, como parte esencial del acervo cristiano (Aquino, 1960: 1089-1093); la Neoescolástica, en especial, aunque no exclusivamente, el legado del jesuita Francisco Suárez, cuyos escritos y enseñanzas sobre el derecho a la resistencia ante la tiranía, aunque fueran prohibidos por los Borbones, continuaron siendo leídos en América (Guerra, 1992: 78); la Ilustración, pero una que fue Liberal y Católica, a la vez (Vázquez, 2019: 345-355), propia del mundo Hispánico, que, como tal, compartió elementos generales de la Ilustración francesa como, por ejemplo, la exaltación de la razón, el afán por el desarrollo y la difusión de la ciencia y del progreso, así como la defensa de las libertades y los derechos individuales; pero que, desde el punto de vista religioso, no fue anticlerical (Jaramillo, 1994: 78-79). En últimas, se trató de una Ilustración Piadosa que fusionaba "la ideología moderna junto con la ideología católica”, razón por la cual, el periódico santafereño Correo Curioso, en 1801, aclaraba que la ilustración debía darse "bajo la luz del cristianismo, guardando las normas y los valores de la Iglesia" (Penagos, 2016: 281-283). Finalmente, se tuvo en cuenta una corriente teológica, el Jansenismo, importada desde Francia a España, con la llegada de los Borbones, que apoyaba las tesis regalistas y conciliaristas promovidas por la monarquía durante el siglo XVIII (Smith, 2010: 25-53). Estas tesis jansenistas aunque fueron conocidas en la Nueva Granada, no tuvieron aceptación entre los fieles de este virreinato, o no, por lo menos, durante el período estudiado (Mestre, 2003 cit. por Calderón y Thibaud, 2010: 132; Sanz-Díaz, 1978: 229).

\section{Conclusiones}

Elanálisis del pensamiento político-teológico en la Nueva Granada, nos ha llevado a identificar unos argumentos y, o elementos conceptuales comunes: el origen del poder, el gobierno según justicia, la concepción providencial de la historia, al lado de la guerra justa. Y dos planteamientos político-teológicos opuestos: el absolutismo, acompañado por el regalismo; y la neoscolástica y el Liberalismo católico. Ya dijimos que la comparación entre los argumentos de los dos bandos en contienda ha permitido verificar que en varias ocasiones unos y otros defendieron distintas causas, la realista y la independentista, a partir de exactamente los mismos argumentos de esta índole. Veamos, por ejemplo, la defensa del "gobierno según justicia" (Amores, 2011: 131-152). Es claro que el pensamiento político teológico católico defiende la idea de un gobierno justo, el cual, en el ámbito hispánico del Antiguo Régimen, suponía la búsqueda, por parte del monarca, del bien común, el respeto a los fueros y a los derechos de las distintas corporaciones, así como el respeto y la defensa de la religión (Amores, 2011: 131-152). De esta forma, resulta que, para los realistas, Fernando VII era visto como un buen rey, porque precisamente creían que era un rey justo, entre otras razones, porque era un rey piadoso (Torres y Peña, 1808: 183). Por su parte, los independentistas también, en aras de la justicia, buscaron la separación de España, al entender que el gobierno de la monarquía era tiránico, entre otras razones, por su marcado 
regalismo en detrimento de la autoridad del Papa y de la autonomía de la Iglesia (Lazcano, 2010: 28).

Una segunda conclusión se refiere al hecho de que la Ilustración católica propuso dos formas político-teológicas completamente distintas. Por una parte, el Despotismo Ilustrado, como es claro, defensor del Absolutismo, fuertemente regalista y conciliarista (Finestrad, 2001). Y, por otro lado, un tipo de Liberalismo Católico que, en su lucha a favor de la independencia, asumió la defensa de los derechos de la Iglesia bajo los nuevos gobiernos republicanos. Esta actitud se reflejó en las Constituciones que se promulgaron durante la llamada la Patria Boba ${ }^{6}$ Al examinarlas, encontramos que estas Constituciones fueron defensoras de las libertades individuales, la división de poderes, la tolerancia religiosa, y la autonomía de las potestades civil y religiosa. Pero también estas se proclamaron defensoras de la Iglesia, asumiendo el catolicismo como religión única y verdadera, $\mathrm{y}$, por tanto, con un estatus privilegiado bajo estos nuevos gobiernos?.

Una tercera conclusión se relaciona con que no encontramos, entre quienes defendieron la causa de la Independencia, una dicotomía entre una corriente neoescolástica y otra liberal ilustrada. Esto ya lo había explicado Francisco Javier Guerra al proponer una síntesis que diera cuenta de las particularidades de la modernidad en el mundo cultural Hispánico (Guerra, 1992: 170; Sarasola, 2012: 103-168). De esta forma, hay que subrayar el hecho de que las quejas frente a la tiranía se remitieron a los argumentos de la neoescolástica, por ejemplo, al reclamar la soberanía tras el vacío de poder que dejó la invasión napoleónica; o al exigir con nostalgia los derechos tradicionales que el pueblo había perdido tras los excesos del absolutismo y del regalismo, especialmente en el siglo XVIII, bajo los Borbones (Campo y Larraondo, 2012: 166). Pero, por otro lado, hay que aclarar que las soluciones propuestas e implementadas durante la Patria Boba y la Gran Colombia (182130), no pretendieron un retorno a la tradición. Propusieron soluciones de corte liberal, modernas, pero, como ya hemos dicho, en concordancia con una Ilustración y un Liberalismo propios del mundo hispánico. Y resulta que este tipo de Liberalismo Católico, en el aspecto político-religioso -insistimos- no reñía con la tradición neoescolástica. Así, los defensores de la independencia en Nueva Granada proyectaron regímenes políticos desde una concepción ilustrada y liberal católica heredera de algunos elementos esenciales de la tradición neoescolástica, como fueron la concepción sobre el origen y fin del poder (Dios y el bien común), la soberanía popular y el contractualismo, así como de aquellos relativos al estatus que la Iglesia debía detentar en las sociedades republicanas del Nuevo Régimen. Me remito a Joseph Pérez, quien, refiriéndose a un contexto político y cultural afín, el de los constituyentes de Cádiz, afirmó: “los liberales invocaban la tradición para destruir el Antiguo Régimen" (Pérez, 2014: 403).

Finalmente, el pensamiento político teológico de la Independencia refleja las tensiones, conflictos, continuidades y rupturas del complejo proceso de transición entre tradición y modernidad, en el marco de la secularización, que se extendió a lo largo del siglo XIX, proceso histórico que para ser abordado, creemos requiere de explicaciones que den cuanta de la dinámica propia del mundo 
de las ideas, en los niveles de realidad propuestos; y a partir del análisis de las características y componentes propios del pensamiento político-teológico aquí descritos.

\section{Referencias citadas}

Amores, J. B. (2011): “'Gobernar según justicia' ”. Realistas y patriotas en Nueva Granada: 1810-1816", en Saranyana, J. I. y J.B. Amores, eds., Política y religión en la independencia de Nueva Granada, Madrid, BAC, pp. 131-152.

Aquino, T. Santo (1960): “De la Sedición”, en F. Barbado Viejo, ed., Suma Teológica, VII, Madrid, BAC.

Arce, V. (2012): "La Biblia como fuente de reflexión política en los sermones neogranadinos, 1808-1821”, CS, 9, pp. 273-308.

Artuñano, S. (2010): San Agustín: La Ciudad de Dios, Madrid, Tecnos.

Braudel, F. (1979): La larga duración en la historia y las ciencias sociales, Madrid, Alianza.

Bossuet, J. B. (1789): Política deducida de las propias palabras de la Sagrada Escritura, dirigida al Serenísimo Señor Delfín: I, Madrid, Imprenta de Don Pedro Marín.

Campo y Larraondo, M. del (2012): Rasgos poéticos que pueden servir de apuntamientos sobre la historia de nuestra revolución escritos por el doctor Mariano del Campo y Larraondo, en M. Revollo, transcripción y comentarios, Chía, Universidad de La Sabana.

Calderón, M. T. y Thibaud, C. (2010): La majestad de los pueblos en la Nueva Granada y Venezuela, 1780-1832, Bogotá, Taurus, Universidad Externado de Colombia.

Claraval de, B. (2005): "Elogio de la nueva milicia templaria”, en R. Pernoud (ed.), Los Templarios: Madrid, Siruela, pp. 39-79.

Colegio Revisor y Electoral (1812): Constitución de la República de Cundinamarca reformada por el Serenísimo Colegio Revisor y Electoral, Santafé de Bogotá, Bruno Espinosa de los Monteros por D. Nicomedes Lora.

Fernández de Sarasola, J. (2012): “La dimensión política de Jovellanos”, en AA.VV, Jovellanos: el hombreque soñó España, Madrid, Encuentro, pp. 103-168.

Finestrad de, J. (2001): El vasallo instruido en el estado del Nuevo Reyno de Granada y en sus respectivas obligaciones, transcripción e introducción de M. González, Bogotá, Universidad Nacional de Colombia.

Gómez Hoyos, R. (1962): La Revolución Granadina de 1810: ideario de una generación y de una época, 17811821, Bogotá, Temis.

Guerra, F. X. (1992): Modernidad e independencias, Madrid, Mapfre.

Jaramillo, J. (1994): “El conflicto entre la conciencia religiosa y la ciencia moderna: Mutis y Caldas", en La personalidad histórica de Colombiay otros ensayos, Bogotá, Áncora, pp. 72-98.

Koselleck, R. (2001): "Sobre la antropología de las experiencias del tiempo histórico", en Los estratos de tiempo: estudios sobre la historia, Barcelona, Paidós, pp. 35-92. 
Koselleck, R. (2004): “Historia de los conceptos y conceptos de historia", Ayer, 53, pp. 27-43.

Lazcano, R. edición, prólogo, notas e índice (2010): "Prólogo", en Fraile M. Miguélez, M., Jansenismo y Regalismo en España (Datos para la historia). Cartas al Sr. Menéndez Pelayo, Madrid, Editorial Agustiniana, Guadarrama, pp. 9-45.

León, A. de (1816): Discurso político moral: sobre la obediencia debida a los reyes, y males infinitos de la insurrección de los pueblos de Santafé de Bogotá, Santa Fe, Bruno Espinosa.

Mestre, A. (2003): "La influencia del pensamiento de Van Espen en la España del siglo XVIII, en Apología y crítica en el siglo XVIII, Madrid, Marcial Pons Historia, pp. 289-319.

Montenegro, W. (2006): Introducción a las doctrinas político-económicas, México, Fondo de Cultura Económica.

Nariño, A. (1811): Suplemento a la Bagatela 5, Santafé de Bogotá, Bruno Espinosa de los Monteros.

Nariño, A. (1823): Los Toros de Fucha, Bogotá, Espinosa.

Olano, H. A. (2014): “El derecho eclesiástico del Estado colombiano de 1811 a 1991”, Hispania Sacra, 66, No. Extra 2, pp. 421-455.

Ortega, F. y Y. Chicangana-Bayona (2012): Conceptos fundamentales de la cultura política de la Independencia, Bogotá, Universidad Nacional.

Penagos, J. (2016): “Modernidad y revolución: la 'Ilus- tración Piadosa' en la Nueva Granada (1808-1816)", en S. Roncallo, S., E. Uribe-Jongbloed y E. Gutiérrez, eds., Identidades, héroes y discursos en la Modernidad tardía, Chía, Universidad de La Sabana, pp. 273-296.

Pérez, J. (2014): Historia de España, Barcelona, Crítica, Planeta.

Saranyana, J. I. (2011): "Política y religión en la insurgencia americana. Conclusiones generales”, en Saranyana, J. I. y J. B. Amores, eds., Política y religión en la Independencia de la América hispana, Madrid, BAC, pp. 229-239.

Smith, A. J. (2010): "Bourbon Regalism and the Importation of Gallicanism: The Political Path for a State Religion in Eigteenth Century Spain”, Anuario de Historia de la Iglesia, 9, pp. 25-53.

Suárez, F. (1970): Defensa de la fe, Madrid, Instituto de Estudios Políticos.

Torres y Peña, J. A. de (1808): “Expresión de los sentimientos de la religión y el patriotismo, Que en la fiesta de la acción de gracias por la proclamación que hizo el Cabildo Justicia y Regimiento de la muy noble y leal ciudad de Santafé de Bogotá, capital del Nuevo Reyno de Granada, por nuestro católico Monarca el Señor don Fernando Séptimo Rey de España e Indias. Pronunció D. José Antonio Torres y Peña cura doctrinero de Enemocón Pueblo de la Real Corona, de la jurisdicción del mismo Cabildo. Con las licencias necesarias. Reimpreso en la Patriótica de Santafé de Bogotá, Calle de los Carneros, Año de 1808”, en Hernández de Alba, G., transcripción, prólogo y notas (1960): Memorias sobre los orígenes de la Independencia Nacional, Bogotá, Kelly, pp. 163-183. 
Uprimny, L. (1952-1954): “Capitalismo calvinista o romanticismo semiescolástico de los próceres de la Independencia colombiana: réplica al profesor Alfonso López Michelsen, Revista Javeriana, 3-6, pp. 135-149, 147-175, 113-153, 87-148.

Vallespín, F. (2012): “Aspectos metodológicos en la Historia de la Teoría Política", en Vallespín, F. ed., Fundamentos de la Teoría Política, vol. 1, Alianza, Madrid,pp. 21-56.

Vázquez, M. R. (2019): “Ilustración católica y argumentos político-teológicos en la Independencia de la Nueva Granada”, Hispania Sacra, 71 (143), pp. 345-355.

Vitoria de, F. (1928): Relecciones sobre los indios y el derecho de guerra: con trozos de la referente a la potestad civil, Madrid, Espasa-Calpe.

Vitoria de, F. (1995). "Lectura 137. Si los preceptos judiciales fueron dados convenientemente con relación a la convivencia de los pueblos", en L. Frayle Delgado (Estudio preliminar y traducción), La Ley: 129-135, Madrid, Tecnos.

VV.AA. (2009): Diccionario político y social del mundo iberoamericano. La era de las revoluciones (1750-1850), Madrid, Fundación Carolina, Sociedad Estatal de Conmemoraciones Culturales, Centros de Estudios Políticos y Constitucionales.

\section{Notas}

1 Este artículo es una actualización de la ponencia presentada en el II Congreso de Historia de la Iglesia (Chile, marzo del 2018), con el título "Ilustración católica en la Independencia de la Nueva Granada”, como parte del proyecto de investigación: La relación entre política y religión: un examen de la filosofía política desde la primera modernidad hasta la postmodernidad (HUM48-2012), Facultad de Filosofía y Ciencias Humanas (Universidad de La Sabana), Entidad Financiadora: Universidad de La Sabana.

2 Campo y Larraondo, 2012.

3 El Archivo Histórico Cipriano Rodríguez Santa María, conformado por los fondos Manuel María Mosquera y David Mejía Velilla, se encuentra abierto a los investigadores desde el año 2013, en la Biblioteca de la Universidad de La Sabana, Chía (Cundinamarca, Colombia).

4 Recordemos que ya Braudel había planteado la larga duración histórica (Braudel, 1979). Por otra parte, es importante tener en cuenta la propuesta de Koselleck sobre los tres estratos temporales: unicidad, reiteración y trascendencia. En este último entrarían las cosmovisiones e ideas religiosas, de larga duración, y ritmos más lentos en el tiempo (Koselleck, 2001: 35-92).

5 El politólogo Walter Montenegro propuso tres elementos constitutivos de las teorías políticas, en la Edad Contemporánea: análisis del pasado, estrategias para obtener el poder y mantenerlo; y proyecto futuro de orden social y político (2006: 24-27). A partir de dicha propuesta trasladamos el análisis hacia las características generales del pensamiento político-teológico. En este mismo sentido, es importante recordar que Koselleck hizo referencia a la manera como los conceptos políticos no sólo se relacionan con las "experiencias que reflejan", sino que "pretenden alguna clase de cambios en sentido social, político o incluso religioso". Así, por ejemplo, el concepto “Estado”, que 
comprende la interpretación sobre una experiencia, en un momento dado, se convierte en un término orientado a promover otras nuevas. De esta forma, el concepto se "enriquece con un contenido utópico". Por lo demás, explica Koselleck, entre menor contenido experiencial tenga un concepto, supondrá una mayor carga de expectativas, hecho que se evidencia en los planteamientos de tipo utópico, algunos de ellos con "reminiscencias teológicas", puesto que las profecías incumplidas aumentan dicha carga de expectativas de forma reiterada (2004: 36-39).

6 Período comprendido entre 1810-15, denominado así por el precursor de la Independencia de la Nueva Granada, Antonio Nariño, debido a la disgregación y convulsión política caracterizada por las guerras entre centralistas y federalistas, lo mismo que entre capitales de provincia y poblaciones sujetas a ellas; así como entre independentistas y realistas (Nariño, 1823).

7 Colegio Revisor y Electoral, 1812: Título 1: Art 1.

No. 2. Olano, 2014: 436. 